\title{
DEVELOPMENT OF TRANSVERSAL COMPETENCES IN SCHOOL EDUCATION (A DIDACTIC INTERPRETATION)
}

\begin{tabular}{l}
\hline \\
South-West \\
\hline A R T I C L E I N F O \\
Studies and Articles \\
Received: February, 02.2017. \\
Revised: October, 18.2017. \\
Accepted: November, 11.2017. \\
doi:10.5937/IJCRSEE1702129T \\
UDK \\
37.02 \\
371.31 \\
\hline
\end{tabular}

\section{Keywords:}

the nature of the relation compe-

tence -competency,

transversal competences,

development of transversal competences - didactic concretization of approaches,

principles and conditions.
Dr. Nikolay Tsankov, Faculty of Pedagogy

E-mail: ntzankov@swu.bg

\begin{abstract}
A B S T R A C T
The contemporary socio-cultural and educational situation points the attention to the analysis and construction of opportunities for the formation and development of transversal competences in school education. It is expedient therefore that within the process of education in all school subjects and throughout all ages and cognitive activities the decisions for the design of a suitable educational environment should be systematized and specified in such a way as to guarantee that knowledge and skills can be continuously regrouped in accordance with context. In other words, these skills and the knowledge they are based on, should form the foundation of transversal competences that can be applied regardless of age and activities. The design of invariant technologies for the development of transversal competences is also related to the coordination of a variety of approaches, principles and conditions of education in such a manner as to provide effectiveness when these technologies are specifically applied as variants. This creates a necessity for a didactic interpretation of the means of development of transversal competences. Additionally, it poses a necessity to improve teachers' special preparation and qualification to design educational environment that can guarantee the achievement of transversal competences as an educational outcome. The present research offers opportunities to realize this goal in an integrative and integrating process rather than as an isolated endevour on part of the teachers or as an unorganized effort on part of the students. This in turn poses some new requirements to the system of school education as a whole.
\end{abstract}

(C) 2017 IJCRSEE. All rights reserved.

\section{INTRODUCTION}

Transversal competences as an opportunity to orient the goals of education towards the personality and make it relevant in terms of the individuality of learners are an expected educational outcome and a key factor for the cultivation of all other specific competences. One of the most important tasks of education is to form and develop competences, especially transversal ones, which are basic and guarantee that individuals can handle their future roles. They are the foundation of all other special abilities and Corresponding Author

Dr. Nikolay Tsankov, Faculty of Pedagogy, South-West University ,Neofit Rilski“، - Blagoevgrad, Bulgaria

E-mail: ntzankov@swu.bg

This work is licensed under a Creative Commons Attribution - NonCommercial - NoDerivs 4.0. The article is published with Open Access at www.ijcrsee.com skills (Merdzhanova, 2005: 61). This requires a continuous search for new methods and skills to facilitate the development of students in such a way as to bring systematicity and durability of knowledge in the form of transfering of skills and competences to new situations. The solution to these didactic tasks requires a complex approach which arguably lies in the design of the school educational environment. This can guarantee the formation and development of transversal competences and the preparation of teachers to perform this task. While searching for ways to reach such educational results and to formulate the criteria for their evaluation, a new methodology of contemporary education is being constructed, which is applied within the competence-based approach. Its nature reflects new realities, such as social needs, economic priorities and dominant trends in the globalizing world. This is why the goals of contemporary education are also associated not so much with the acquisition of knowledge, skills and habits in 
a specific area, but with the development of human values and with the formation of an integral (interdisciplinary) perception of reality - real and virtual, together with the respective abilities. In this sense, the competence-based approach is grounded in the modern paradigm for the development of interdisciplinary science and technology and in an education that integrates their achievements.

\section{COMPETENCE, COMPETENCY, TRANSVERSAL COMPETENCES - CONTEXTS OF UNDERSTANDING}

Terms are invented to reflect the phenomena and the subjects they signify. We simply use them to designate entities. This applies to the term competence, which has had long evolutional development since it was introduced in the XX century. This is why the phenomenon competence has been known long before there was any definition for it. From the distant past there have been spiritually elevated people, often with encyclopedic knowledge, who reached great heights in a variety of activities - art, science, technology. Now competence emerges in more specific, mostly professional activities. This type of competence far exceeds the understanding of expertise, experience, education and skill.

Very often emphasis is placed on the conceptual pair competence/competency, aiming at their identification and meaningful distinction, as well as their further differentiation into different types and varieties. A number of studies and analyses highlight literacy and competence as key concepts in modern education, with competence in education science being a basic construct, often analyzed as an integral personality quality, as a system of competencies structured in a particular way that integrates knowledge and skills in a specific context and enables a person to adequately manifest their practical skills demonstrating attitude to oneself, to others and to the activity and its results (Tsankov, 2012: 44). There are two main approaches to clarifying the relation competence/competency: (1) their consideration in the context of normative (objective) and subjective (personal) determination, and (2) as a conceptual-event pair.

The comparative semantic analysis shows lexical differences between the concepts competence and competency, which, according to a variety of authors, differ in their meaning and content: "Competencies are manifested through the respective action in the context of a certain practical activity based on the aqcuisition of a complex of knowledge, skills, experience and legal prerogatives of a person within a limited area (...), while competence, as a concept, is wider in meaning and richer in content. It is associated with a personality quality, characteristic feature, a basic trait of the individuality and demonstrates completeness, the outcome of an action or activity" (Naydenova, 2004: 65). The concept competence is thus related to the ability for functional performance in a professional environment by demonstrating behaviour that meets its requirements (Burke, 1989). Despite its limitations, the above definition gives grounds to explore competence as a type of behaviour which makes it possible to appreciate not what the subject knows, but how, when and whether this knowledge is applied to prictice in a specific activity or context through the relevant skills and relations. For this reason competence is analyzed as an opportunity to perform an activity in a potential manner, which is manifested and demonstrated in and through professional, educational or other kind of activities exerted with the help of the respective competencies, standards and requirements. In this sense, "competency is always bound with the operationalization of subjective manifestation, while competence can be considered in its potential detachment from direct practical experience" (Velikova, 2003: 16). To a certain extent, this position is in accordance with P. Radev's view that competence is one of the constructs of educational sciences which is "hypothetical in essence; a product of theoretical research and the human ability for abstraction; a concept; a category", which is manifested in the reality of education through the event "competency" defined as "what really happens; productive acts and actions; referents of the constructs; a part of reality" (Radev, 2005: 130).

Regardless of the variety of clarifications concerning the two concepts, there is still no unanimity of opinions in the interpretation of their content, which, according to some authors is unacceptable for purely technological reasons (Prange, 1995: 147), because these concepts are considered from diststinct positions - theoretical, phenomenological, constructivist, holistic, etc. Still, certain researchers use selectively either one or the other concept, while others apply them synonymously. G. Selevko attempts to reveal their semantic nuances based on the 
dictionary approach by adopting the view that competence is the more general concept and defines it as "the ability of a person to handle the respective competency, including their individual attitude towards that competency and the object of the activity it is engaged in" (Selevko, 2004: 139-140). There is also a more generalized interpretation of "competence as a generic concept (...), representing a complex system of competencies, considered as a type of concept (...) to denote the strategic educational goal" (Naidenova, 2004: 71).

Competence implies at least a minimal attempt to apply the relevant competency. Therefore, the notion of competency refers to the outcome of education - preparedness, adaptability, achievability of objectives, and competence is most often understood as an integral personality quality, manifesting itself as a general ability and willingness to work based on knowledge and experience which are acquired in the process of education and socialization and are oriented towards independent and successful participation in the activity" (Selevko, 2004: 139-140). The more pragmatic views of competence are related to its consideration as the ability of the person (the student) to carry out an activity that is personally or socially significant as a "complex skill" or "complex ability" (Zimnaya, 2006: 139). Starting from the complex nature of competence, J. Raven believes that its higher order development in students requires that they should be motivated for its application in performing an interesting activity: "In order to facilitate this process, the teacher is obliged to determine the propensities, interests and competence of his students and to observe the changes while they gain experience" (Raven, 1999: 65). As a psychological and pedagogical category, the concept competency is difficult to distinguish because it encompasses a "complex of generalized modes of action, of productive performance of the activity, and the ability of a person to realize their competence in practice" (Temyatkina, 2006: 7).

A. V. Hutorskoy, on the other hand defines the concept competency as "a complex of qualities necessary for one's functioning in a specific area of an activity, while competence is the handling of the respective competencies, i.e., a personality quality which has already been applied or a set of qualities and minimum experience in the performance of an activity in a perticular sphere" (Hutorskoy, 2003: 58).

The discussion above demonstrates both overlaps and differences in researchers' opinions concerning the content of the two con- cepts. The present paper will not consider in detail these differences because their nature is predominantly formal. Moreover, pedagogical practice specifies competencies in terms of their content through educational requirements- the standards at all the levels of studying school subjects. What is considered here of greater importance is the differentiation between the concepts competency and competence in order to avoid their synonymous or interchangeable usage. The following claim suggests a solution which is, to a certain extent, acceptable: "The first (competence) is more normative and 'detached' from the personality, while the second (competence) is considered to be an integral quality, close to intelligence (...) Given the undeniably personalized nature of the competence approach, it can be concluded that its essence is formed on the basis of the meaningfully distinctive and conceptually revealing term competence" (Genkova, 2007: 439). The above clarifications underscore the understanding that the competence of a student/ person represents an individual integrative personality quality manifested in the manner of organization and application of knowledge and skills. This quality facilitates effective behaviour and decisions in a variety of situations. This more or less didactic interpretation can be complemented from a psychological perspective when regarded as "a capacity in the form of ability or skill of the individual to cope effectively in their environment; a quality of a person to apply a set of behaviour models which affects selectively and successfully their material and social surrounding in view of their needs, goals and intentions" (Desev, 1999: 160). This interpretation of competence as a psychological phenomenon shows that it is connected with all subsystems of the personality, with its development as a whole, and with the results of its selfperfection. The complex phenomenon and concept competence (designated by a singular collective noun) comprises all the components of the personality system related to the formation and development of the individual as a result of communication and performance in a variety of surroundings - family, school, society, etc. It is to be manifested differently in everyone and depends on the nature of the Self, on one's individual proclivities, interests, motives and the environment which forms them. Certain good practices and educational experience can be used as a basis for the design of procedures for the development of competences in students. This, however, poses the question about their types and specific 
manifestations. It is clear that competence has its forms, which need to be explored and developed in accord with the educational and professional competencies expected by society.

In V. Delibaltova's view competence is a personality characteristic which cannot be operationalized by reiteration into separate fragmented "discrete" bits of knowledge and skills. Rather it should be evaluated in context on the basis of the effective performance of a task or activity, not as the achievement of a standard that has been set (Delibaltova, 2003: 12).

Before defining and presenting the key features of the concepts competence and competency and substantiating their content on the basis of the approach that treats them as a conceptual-event pair, it is necessary to define the terms concept and event.

The science of education defines as concepts all categories (constructs) which have a hypothetical nature and are products of logical thinking and theorizing used to describe, explain and conceptualize a problem. Different categories fall into the group of these constructs or concepts: intellect, goal orientation, knowledge, skill, competence, ability, motives, etc. This gives grounds for the definition of the concept of competence as an integral personality characteristic manifested as a series of events (as part of reality) in which the individuals are involved through their competencies.

In general, the event does not last long, it is something that happens as a specific change which can be established and registered. Clarifying the essence of the concept of "situation" and "event", J. Lyons acknowledged that the "situation" could be both static and dynamic. The static situation (state) is homogeneous, prolonged and does not change during the period of its existence, while the dynamic situation is subject to change, characterized by different temporal contours and is not always homogeneous. According to the author, depending on the duration of the dynamic situation, two main types are formed - a process, if it runs over a wide interval of time, and an event, if the situation is momentary (Lyons, 1977: 483). A debate about the essence of the concept of event occurs in the field of cognitive linguistics, where it is referred to as a "cognitive phenomenon of varying degrees of complexity" (Langacker, 1987: 100).

In defining the nature of the concept event, L. Talmy introduces the notion of "frame of the event" as "a set of concep- tual elements and the relationships that hold between them that are invoked in the mind together or mutually, fall into or form the framework of the event, while elements that are conceptualized as random - regardless of whether they are weakly addressed or not addressed at all - remain outside the framework of the event"(Talmy, 2000: 259).

The difficulties in distinguishing the two concepts necessitate their unification into the conceptual-event pair competence/competen$c y$, which came into use in the $1990 \mathrm{~s}$, when not only researchers, but also experts from various international organizations, as well as educational practice itself became interested in their classification, formation and development. Nevertheless, as a paradigm for modern education, most authors accept the notion of competence, and it is manifested in reality as an educational, professional and life variety, as expertise, professionalism and skill.

Applied to the conceptual pair under consideration, the discussion above gives grounds to conclude that competencies (integrated into a specific situation and context of knowledge and skills) are event referents of the concept competence as an integral personality property. Competency is actualized and subjectively manifested competence. Thus competency is primarily subjective and personal, while competence - an objective and normative characteristic of human activity. Competence is not limited to cognitive elements (including the application of theories, concepts, or implicit knowledge), but it also comprises functional aspects (social or organizational skills) and ethic values (Radev, 2013: 178).

Based on the systematized views on competence and competency made by $\mathrm{N}$. Tsankov, Y. Merdzhanova summarizes that that competence is mainly related to "potential capabilities", "effectively performed activity", "emotional aspects giving meaning to the activity", while" competency" has a more pragmatic aspect as " a practical realization of competence", as an awareness "how to implement a connection between knowledge and situation". The etymology of the two terms refers to the authentic meaning of competence as "appropriate, relevant, capable, meaningful" and of competency as "accountable, matching, capable" (Tsankov, 2012; Merzdhanova, 2014).

From the above analysis some conclusive remarks can be made about the notions of competence and competency as elements of a conceptual-event pair: (1) competence is an integral personality quality, a system of com- 
petencies structured in a particular way which integrates knowledge and skills and the attitude of the individual to him/herself, to others and to the activity and its results; (2) transversal competences develop in specific contexts and offer opportunities for adequate practical realization of the individual. This conclusion is also confirmed by Y. Merdzhanova's summarized views on the essence of competence, namely that it is a system of rational, affective and pragmatic capabilities that guarantee successful behavior in a certain situation that can be segmented into behavioral patterns and formed in education (Merdzhanova, 2005: 6263).

As regards their role in education, competencies are formulated as goals and are officially included in educational standards as educational outcomes, while competence is a personality quality of the students (value orientations, knowledge, skills, habits and abilities), predicated on their functional experience in a socially or individually significant sphere hence in their future careers. Y. Merdzhanova offers an adaptive, integrative and holistic model of competences in which the cognitive ones are associated with the development of knowledge, the functional ones - with the acquisition of skills, the social ones - with interpersonal relations and behavioral patterns, and metacompetences are fundamental with respect to the others and have an integrating effect, transforming them into transversal competences that can be applied irrespective of age, activities and context. A differentiation can be made between metacompetences and core competences, based on the argument that with core competences it is not their fundamental nature that is important, but the universality of their application. They are applied through different situations (trans-situational) and can be transposed in view of the current needs. This, however, does not contradict the possibility for them to be formed and developed as transversal (Merdzhanova, 2014: 12).

Within the implementation of the competence-based approach in education, different types of competencies are identified and analyzed: key competencies (relevant to general educational content and basic in nature, universal and transferable to different educational, professional and life situations); basic competencies (reflecting the specific nature of a particular professional activity), functional competencies (a set of activity characteristics reflecting a set of functions specific to a given job), educational competencies (a set of conceptual orientations, knowledge, skills, habits, and experience in the student's activity in relation to a certain set of objects of reality necessary for the realization of personal and socially significant productive activity): general subject competencies (related to a certain range of subjects and educational fields) and subject competencies (having a specific description and a potential to be formed within a given subject).

Key competences, i.e. competences which have been ivested with personality relevance through education, are a system of knowledge, skills, attitudes and relationships that help learners and job seekers to achieve personal realization by enhancing their choices, increasing their adaptability to the dynamics of living and working conditions by making people more social, mobile, competitive and motivated. This makes key competences crucial for the development of individuals, their competitive advantage and their opportunities for adaptation and social inclusion.

In the negotiation of the tenets of the theory of transversal competences, the conclusion grows increasingly popular that it is necessary to provide conditions for the building of skills that override the constraints of school subjects in the formation of a general system of knowledge, skills and behavior that have informational, methodological, social, personal and communicative character and guarantee the formation of capabilities to confront and resolve complex life situations, which are, in fact, the authentic situations faced by the person.

The term transversal does not refer to the common elements of the individual competences in a certain school subject. Rather, it addresses the additional content of these competences (over and above the content related to any specific school subject) which can be used in other areas. It is precisely this portability and flexibility of key competences that make them "an invaluable tool for successful action in a rapidly changing environment", in which purely school subject competences have a limited range of efficiency. But here a problem arises because "any competence is in its essence limited and related to a certain object, hence - it refers to a specific area" (Ray, 1996: 26).

Looking for a way out of this inherently controversial situation, Y. Merdzhanova considers competence not only as a function but also as an intention, i.e. as a point of view, an approach or style, making it possible and necessary "to be formed pedagogically and to be transmitted through ages and activities. 
This is the meaning that each individual attributes to the situations in which he operates through his narrow competencies" (Merdzhanova, 2002: 100). Together with the transversal competences of students, a number of specific competences are formed at the level of school subjects, but their description, systematization and hierarchical arrangement are a matter of other, more specific methodological studies. Such studies may reveal a greater specificity of the application of basic transversal competences, such as the information, the communication, the cognitive competences, and others. With respect to communication as a phenomenon, M. Levunlieva argues that "it is in the context of communication that human relations come to be realized, negotiated and sustained", (...) which is "vital for the maintenance of a healthy social environment" (Levunlieva 2012: 173). Thus communication competence stands out as one of the most important competences, along with the above mentioned basic transversal competences, and serves as a foundation for the formation of a functionally adequate individual.

Distinguishing between two aspects of competence, as a function and as an intention, Y. Merdzhanova emphasizes that competence as intention can be developed with pedagogical means and has to be passed on through ages and activities. She defines four basic transversal competences: autonomy and responsibility, communication competence, organizational and methodological competence, cognitive competence for information processing. (Merdzhanova, 2005: 62).

The characterization and classification of transversal competences include (La définitionet la sélection des compétencesclés.http:// www.oecd.org/dataoecd/36/55/35693273.pdf (24.04.2017).): (1) multidimensional, involving different processes and intellectual abilities - analytical, critical, communicative, etc.; (2) multifunctional, whose mastering allows students to solve various problems in everyday, professional and private life and whose acquisition is an instrument to solve tasks in different situations; (3) cross-disciplinary and interdisciplinary, which are applicable in different situations within and outside the school context; (4) competences related to the overall development: abstract thinking, self-reflection, self-standing, individual stand, critical thinking, etc. The very essence of transversal competences as described above requires the search for methodological approaches to the design of the educational environment which guarantees their forma- tion and development in school education.

\section{APPROACHES AND PRINCIPLES FOR THE DEVELOPMENT OF TRANSVERSAL COMPETENCES}

The vision for the need of active participation of the student in the cognitive activity is not new. Contemporary conditions, however, call for its transformation into a basic philosophy of life and a main path for personal development corresponding to the continuous changes and innovations characterizing the development of the society in the 21 st century that affect the modern human. This transformation requires a reconsideration of personal development and of the educational paradigm as a whole and is related to the formation of a new consciousness and value orientation in everyone. This requires: 1) redefining the goals of education; 2) paying special attention to students' needs and learning motives; 3) introducing adaptive teaching strategies; 4) designing a dynamic environment which supports learning - flexible, mobile, guaranteeing interaction and cooperation; 5) reaching a new level of monitoring and evaluating learning outcomes.

Forced by the dynamic changes in social practice, education constantly reforms to which end it uses a specific approach or a combination of approaches, such as the algorithmic one, the heuristic one, the task-based one, the learner-oriented one, etc. An approach that stands out within the set of integrative, learner-oriented, task-based ones, as they produce significant and up-to-date results and have an innovative and conceptual focus, is the competence-based approach, which has acquired popularity in the European Union, the USA, Russia and other countries.

At the core of the design of the educational environment for the formation and development of transversal competences lie the constructivist paradigm, the educational approaches (competence-based, personality-oriented and activity-oriented), the basic principles of education and the conditions that guarantee a new level of the product of education.

The constructivist paradigm is fundamental to the development of transversal competences, and it is based on the possibility to induce cognitive situations related to the purposeful and systematic application of methods 
which facilitate the realization of the cognitive experience, the knowledge of the pupils and their skills to apply them in a specific context according to conditions conducive to their subjective expression and active cognitive activity. The constructivist paradigm is related to the view that ,the learning process is built starting from the instructor's personality, his/ her uniqueness, exceptionality and individuality" (Ivanov, 2004: 32).

Therefore, in the development of transversal competences through the application of different approaches the student is an active subject in the cognitive activity realizing his/ her potential and capabilities.

The essence of the constructivist theory of learning can be summarized as follows: knowledge is constructed, not transmitted; new knowledge is built on the basis of prior knowledge; the initial idea is local rather than global; building knowledge as a set of structures requires targeted activities. Thus constructivism is focused on the process of the search for knowledge and on its formation.

Knowledge is not received as a readymade product but is formed in learners in the process of self-discovery and the transformation of information on the basis of their experience and prior knowledge. The conceptual core of constructivist learning is therefore the activity of students to learn by interacting with each other, with the teacher, and through „doing," discovering and exploring (TafrovaGrigorova, 2016: 76).

Drawing on the constructivist studies, D. Dimova makes the following conclusions: 1) learning, regardless of the area in which it arises (cognitive, affective or psychomotor), always involves the process of individual transformation; people learn by 'embedding', integrating new knowledge and experience into existing cognitive structures; 2) learning and the context of learning are deeply interrelated; the knowledge and their meaning imparted from the outside are internalized through their refraction through the prism of individual experience in a practical context; 3 ) learning is always dialogical, whether it is done directly (by interacting with others) or by interacting with products created by others; 4) social interactions are an essential component of cognitive personality development; 5) the construction of metacognitive abilities (reflection on one's own way of thinking) should be incorporated as an essential and irrevocable part of the learning process. This implies the use of learning methods that direct students ${ }^{6}$ attention to the process of their own learn- ing through reflection and analysis (Dimova, 2013: 26).

Student-centered learning, in which the student is an active participant, is the basis of constructivist strategies according to which learners independently discover and transform new information, by continuously verifying it with old, familiar rules, also subject to revision with respect to the cognitive situation. According to the constructivist learning theory, students must construct knowledge in their own consciousness so as to internalize and absorb it and this requires subject-oriented learning directed primarily towards developing the personality of the students, their ability to solve tasks, as well as their cognitive autonomy, motivation and acts in real situations and conditions. Such situations require not only integrative knowledge, but also relevant competencies and types of competence.

As a major problem for modern education, the system's orientation to memory and reproduction is emphasized, which in turn fails to provoke thinking, autonomy and skill formation. This has been a serious challenge for all educational systems over the past decades, since in the dynamically developing modern world a considerable amount of "ready-made" knowledge is not of particular value and is insufficient for a successful social realization. Such knowledge does not provide an opportunity for creative thinking and decision-making in practical situations.

In today's world of information overload, the school is not the only and, in many cases, it is not even the primary source of information for students. This also predetermines the new role of teachers - turning them from monopolists of knowledge into mediators between information chaos and organized knowledge. In this process new core ideas for modernizing education are being formed: emphasis on skills and competences; free handling of different sources of information; ability for critical and creative thinking; opportunity to transfer knowledge to new situations. Educational standards in secondary schools predetermine the change in teaching and learning, thus rethinking and redirecting the role of the main actors in the learning process - both the teacher and the student. At the same time, for their successful realization, it is necessary to apply such educational approaches and training methods which make the student an active partner in the educational process.

The exploration of the opportunities for the development of transversal competences 
guides the search for approaches related not only to perception but also to the development of technological schemata and models for the realization of knowledge in the form of skills and habits which are bound to become competencies. It is not enough for these competencies to be learner-oriented. Rather, they need to develop within the subject-oriented educational environment in which the student has a central role. This requires that education should provide:

- development of the student's personality as a subject (not as an object) of education;

- active and independent task solution;

- stimulation to student's autonomy and inner motivation by bringing them into contact with the real problems;

- integrative knowledge;

- a teacher who organizes, inspires and achieves the necessary discipline through a rational organization of the cognitive activity of the student.

Creative, educated individuals are needed in all spheres of modern life: politics and business, education, and all professional skills - all of them must have creative thinking. In modern schools the creative development of the personality, the development of culture and intellect is a continuous process, depending on the work of the teachers and the activity of the students. The learning opportunities provided by all school subjects should be updated and used in such a way as to develop their areas related to the activation of students' creative thinking as a basis of their personal development. The ideas for the modernization of education and the introduction of innovative approaches in the learning process are usually limited to:

- students' ability to handle fluently different sources of information;

- acquiring skills and competencies that guarantee subsequent self-development;

- use of modern information technologies;

- development of active, critical thinking and civic position.

The personality-based approach is directly related to the orientation of education towards its core value - the personality of the student. The organization of personalitybased education requires an analysis and interpretation of the following findings (Zeer,
1999: 167):

- developing the personality of the learner is a major goal of learner-oriented education;

- the whole educational process is tailored to the personal components and the specifics of the teenagers;

- the personality of both the educator and the student in the educational process is subjective;

- the main motives for education are the combined self-development and self-regulation of both the teacher and the student;

- ensuring competence through the formation of lasting knowledge, skills and habits, ability to make independent decisions in unusual situations;

- inclusion in the educational process of the pupil's personal experience;

- development of autonomy, responsibility and self-reflection.

Such an approach to the formation and development of transversal competences is in harmony with the understanding of a personality-oriented type of didactic technology through the creation of an individual educational trajectory based the following: 1) the right to choose and express one's individual meaning and purpose in each subject or lesson; 2) the right to personal treatment and understanding of the fundamental concepts and categories; 3) the right to draw up individual educational programs; 4) the right to choose an individual rate of education, forms and methods for solving educational tasks, ways of control, reflection and self-assessment of the activity on the basis of the knowledge about one's individual peculiarities; 5) individual selection of the subjects studied, creative laboratories focused on such types of classes that are in accordance with the basic school curricula; 6) opportunities for a more profound interpretation and handling of the study content of the course for those who are interested in that; 7) individual choice of additional themes and creative activities on school subjects; 8) the right to an individual picture of the world and individually motivated views on any educational field (Hutorskoy, 2001: 276-287).

In learner-oriented education, learning is a student activity discreetly managed by the teacher. The ultimate goal of learning is initially determined by the teacher in several variants. Each student chooses and rephrases a specific goal. Since the goals of the students are different, teachers find themselves in a situation of uncertainty, in which specific rela- 
tions regulating the activity of all the subjects (including the activity of the teacher) must be established (Vassilev, Dimova, KolarovaKancheva, 2005: 71). The personality-based approach is thus seen as a ,special kind of pedagogical process (with specific goals, content, technology) oriented towards the development and self-development of the individual's personal qualities" (Ivanov, 2004: 35). In this context, the development of transversal competences is linked to the vision of the student as a subject acquiring their competence in a cognitive process transforming the teacher from a source of knowledge into supervisor of independent active cognitive activities, creating situations based on cognitive tasks. Thus the teacher participates in their solution as a competent consultant and assistant in case of difficulties.

This can be successfully realized in the course of the formation and development of skills through a personality - oriented technology for enhancing the cognitive autonomy and development of the students' thinking specified as: 1) ability to autonomously transfer the acquired knowledge and modes of action into new situations; 2 ) ability to see new problems in familiar conditions or ability to see the new feature of a familiar object; 3 ) ability to visualize the structure of the object to be studied; 4) ability to see alternative solutions; 6) ability to create original solutions, although other ways are known (Petrov, Atanasova, 2001: 277-280).

The educational process related to the formation and development of transversal competences becomes functional for the personality when there are: motivations (accepting and justifying the activity of systematic and purposeful formation and development of transversal competences); ability to react to external influences and internal impulses of behavior or to see hidden contradictions of reality; criticism of external values and norms leading to a construction of one's own system of meanings; formation of a personal picture of the world; provision for autonomy of behaviour and creative nature of any individually significan activity; selfrealization and level of functionong that is commensurate with personality preferences.

Another approach focused on personality development through active reasoning and purposeful solution of cognitive tasks is the activity-based approach. According to this approach, it is of the utmost importance that a science presents itself to the learners not only as a system of knowledge that has already been built, but also as a system of characteristic problems and tasks, as well as possible ways for their solution. At the core of the activitybased approach, purposeful action is identified as the most important development factor. The activity-based approach focuses on the unity of reasoning and functioning where the latter forms the basis on which the former is built and, depending on the activity. The activity-based approach focuses on: subjective educational interaction, managing the transition from learning activity to activity in life, balancing between cognitive activities in education and self-managed activities, creative focus, and formation of needs for creative and nonstandard performance. In view of the principles of this approach and the positions argued in the present study, transversal competences can be defined as opportunities for manifestation of students' aspiration and ability to realize their potential (their knowledge, skills, experience, attitude and personal qualities) in successful creative (productive) activity. Transversal competences are formed, developed and manifested in the course of this activity because, as opposed to generalized universal knowledge, they have a profound, practical and dynamic character.

This is in line with the persuasion that activity-based learning has three goals: 1) reactivating acquired knowledge; 2) determining required knowledge; 3) building new knowledge in the course of the activity through awareness of needs. In this perspective, learning through systems of cognitive educational tasks must first of all focus on the cognitive work of the learner so that the relevant transversal competences are built in the process of their implementation. Teaching is effective when it corresponds to the level and skill of learners and follows their improvement, gradually transforming into unobtrusive support which runs parallel with the development of students' autonomy. The learner is the subject and the main actor in the process of education and transforms it into a social space for learning and interaction. Ensuring autonomous learning is in line with the understanding that knowledge is not transmitted directly by perceiving passively during teaching but is built through an active dynamic process in which input information is subjected to transformations depending on the students' prior knowledge and their personal learning style.

As a result of the change in the traditional scientific paradigm, learning is interpreted as an active process of individual construction and acquisition of new knowledge based 
on continuous and dynamic interactions in the educational context. The direct participants in the learning process do not only acquire knowledge, but also intensively process and interpret information coming from outside and possess meta-cognitive skills for individual control and self-regulation (Tsvetkova, 2001: $8)$. The more learning skills the students develop, the greater their opportunities become to play the role of co-workers (partners) of the teacher and to be active participants in interactive learning (Gyurova, Bozhilova, Valkanova, Dermendzhieva, 2006: 83).

The topicality of the problem of cognitive interests is associated with the establishment of a new system of values and a learner-centered education that focuses on the learning process as a central one. According to David Kolb's conception (1984), learning takes place in a cycle called the " cycle of learning" consisting of: experience, reflection, conceptualization and application. It is assumed that without these four successive characteristics the learning process cannot be complete. Different people also have different learning styles, according to Kolb. For some, the process starts with the solution of a task; for others this is a matter of thinking and searching for correct theories. Still others are inclined to plan their activities first (Kolb, 1984). Changes in the educational space are prompted by the influence of social development. It is a generally accepted fact that in modern didactics there is theory of active learning underlying constructivism. This theory is based on the need to develop the creative activity and the autonomy of the personality. The development of students ${ }^{6}$ creativity helps them to acquire new methods of knowledge. By solving these problems, education must prepare the future citizens of the world to self-replenishtheir knowledge, to be able to see and correct their shortcomings, to organize their work in the process of continuing education and lifelong learning.

The approaches discussed above, namely the competence-based, as a central one, supplemented by the personality-oriented and the activity-based approach and realized in different combinations, lie at the basis of the present research, together with the ones related to the study of the mechanisms of information processing in the course of learning through educational cognitive activities. These prerequisites to fully optimize the learning process are essential for its exploration, which is itself also related to learning strategies and the methods to improve them.

The basic principles underpinning the development of transversal competences are essentially related to the basic principles of constructivism in education sciences. Constructivism is not a new concept, and its roots can be found in philosophy and anthropology through I. Kant's understanding that rather than receive information passively, people actively and selectively assimilate knowledge by making their own interpretation of reality. Today this understanding has undergone different metamorphoses and has been enriched and developed for various research purposes. Analyzing the philosophy of individual constructivism in education, Pl. Radev points out that "learning is organized as a process of reality modeling actions", in which the pupil progressively forms abstract schemes of these actions building these into his or her learning behavior (Radev, 2005: 123). From the positions of constructivism the author outlines the following principles of education (Radev, 2005: 346):

- Principle of contextuality and situability;

- Principle of stimulating the student's own organization, reorganization, integration and reintegration of knowledge;

- Principle of ensuring the student's own active construction and reproduction of knowledge and experience;

- Principle of self-construction of knowledge based on previous knowledge and experience;

- Principle of interactive orientation of students to tasks and problem solving;

- Principle of integrating research and implementation into learning;

- Principle of a culture-based and differentiated approach to learning.

At the core of constructivism is the idea that the basic functioning of the student's knowledge occurs in situations and "that they [situations] are what establishes the relationship between teaching and learning attributing specific value to students' knowledge, which turns it into situational". It is "the situation that presupposes the use of knowledge, it reorients it towards natural development through training, it provides a point of intersection between developing knowledge and existing knowledge" (Radev, 2005: 306).

This is what V. Gyuviiska uses as grounds to recommend "reconceptualizing the process of learning as an occurrence of being, which will make it possible to recover the students' thought continuum and will invest learning with the authenticity of happening 
[occurrence]" (Gyuviiska, 2012: 270).

In the process of teaching, it is not a matter of priority for the teacher to present truths that are considered to be undeniable, but rather to create conditions that will stimulate the students' thinking, i.e. cognitive situations. It is not enough for teachers to be well acquainted with the content included in the curricula, but they must also have an inventory of pedagogical situations in which learners can use the knowledge they have to construct, the skills underlying modeling as an

Table 1. General characteristics of the principles for development of competence for cognitive modeling in education

\begin{tabular}{|c|c|}
\hline Main principles & Characteristics \\
\hline Dynamicity and activeness & $\begin{array}{l}\text { Requires such an organization of educational activity which excludes passive learning } \\
\text { and orients the process to independent activities for the acquisition and formation of } \\
\text { relevant skills and the development of competence for cognitive modeling in education. }\end{array}$ \\
\hline Durability and continuity & $\begin{array}{l}\text { It presupposes continuity between all levels of education, as well as in training, through } \\
\text { its organizational forms, content, methodological units and technology in the courge of } \\
\text { the formation and development of competence for cognitive modeling. It ensures the } \\
\text { continuity of the application of cognitive modeling through a permanent transfer to new } \\
\text { situations of advanced competence and practical experience through relevant skills and } \\
\text { competences. }\end{array}$ \\
\hline $\begin{array}{l}\text { Comprehensiveness and } \\
\text { complexity }\end{array}$ & $\begin{array}{l}\text { It requires that the student ghould: 1) form a generalized, comprehensive view of nature, } \\
\text { society, and the self building a subjective "model of the world"; 2) disclose and } \\
\text { implement integrative links at the theoretical, thematic and subject level. It provides } \\
\text { complexity and versatility in the study of objects, procesges and phenomena of reality } \\
\text { by using a combination of models. }\end{array}$ \\
\hline $\begin{array}{l}\text { Psychological and } \\
\text { pedagogical comfort }\end{array}$ & $\begin{array}{l}\text { It requires the avoidance of stress factors and situations in the educational process and } \\
\text { predicates the creation of a benevolent atmosphere in class and school based on the } \\
\text { ideas of pedagogical cooperation. It forms a new style of communication which } \\
\text { compensates and counteracts: 1) teachers' lack of attention; 2) the digregard of the } \\
\text { personality of the students; 3) their isolation and low self-esteem. It orients education } \\
\text { to the formation of a value system that is not predetermined by prohibitions and } \\
\text { punishments but is built in the process of meaningful communication and motivation } \\
\text { of the students by directing them towards positive behavioral patterns and attitudes for } \\
\text { competence-oriented education. }\end{array}$ \\
\hline $\begin{array}{l}\text { Symbiotic relation between } \\
\text { visualization and } \\
\text { modelling }\end{array}$ & $\begin{array}{l}\text { The model method is viewed as a realization per se of the principle of visualization. It } \\
\text { is related to the unraveling of the hidden esgence of objects, processes and phenomena. } \\
\text { The model, as a means of visualization and a 'perceptual prompt' within the activity of } \\
\text { modelling, serves as a basis for abstract theoretical thinking. The symbiotic relation } \\
\text { visualization/modeling as an application of perceptual and image elements is important } \\
\text { both to the development of human cognition and to the process of education. The } \\
\text { realization of this principle leads to an increase of the sensory experience of the } \\
\text { students, to the formation and development of the perception, the imagery, the spatial } \\
\text { thinking and imagination, the formation of observation, the creation of conditions for } \\
\text { active perception. This helps the assimilation of theoretical knowledge (conceptual } \\
\text { basis, regularities, construction of operational models, etc.) and in general the } \\
\text { guccessful participation in the cognitive activity. This principle plays an important role } \\
\text { in the setting and solving of cognitive tasks with an increasing level of difficulty } \\
\text { throughout the transition of different cognitive levels.The implementation of the } \\
\text { principle of visualization and modeling in education develops students' comprehension } \\
\text { abilities as a basis for their dynamic cognitive activity. }\end{array}$ \\
\hline Creativity and variation & $\begin{array}{l}\text { This principle guggests: 1) maximum orientation to problem solving and creativity in } \\
\text { the course of the cognitive modeling; 2) transfer of competence in new situations and } \\
\text { through new activities, as well as in the educational activity as a whole. Students are } \\
\text { also gupposed to: 1) acquire their own experience of constructing and solving problems } \\
\text { and tasks; 2) form an ability to develop variants and to choose the optimal option } \\
\text { according to given criteria. }\end{array}$ \\
\hline $\begin{array}{l}\text { Situational constructivist } \\
\text { principle }\end{array}$ & $\begin{array}{l}\text { The actions underlying cognitive modeling in education are realized on the basis of } \\
\text { structured content. This activity only makes gense if it leads to the acquisition and } \\
\text { consolidation of new knowledge on the basis of the independent design, reconstruction, } \\
\text { transposition and modification of students' earlier knowledge and skills. This requires } \\
\text { the creating of conditions for mastering new knowledge based on the activation of } \\
\text { previous knowledge concerning models and modeling and for the building of skills in } \\
\text { the course of deciphering the new cognitive situation. Part of these conditions is to } \\
\text { ensure the dynamics of the contexts of situations so that new knowledge is applied in a } \\
\text { new spxmernm, different from the original one, which leads to the activation of } \\
\text { reflection on cognitive modeling in education as a method uged in different situations. }\end{array}$ \\
\hline
\end{tabular}




\section{CONDITIONS FOR THE DEVELOPMENT OF TRANSVERSAL COMPETENCES}

The development of students' transversal competences is directly related to the use of the cognitive abilities for learning and interpreting knowledge developed to the level of skills. This process requires conditions for providing the problem orientation, autonomy and creativity in its course. Continuous transitions from the concrete to the abstract and the abstract to the new concrete are realized in training. The acquisition of a knowledge system for the specific and the general is a cognitive process, characterized by the continuous design of models, through which students encode, recode and decode information in the course of the incessant transition from the concrete to the abstract and vice versa. This necessitates the deliberate application of logical methods - analysis, synthesis, induction, deduction in combination with the model method as one of the conditions for the development of transversal competences.

The cognitive activity in education is based on the means and resources of a certain subject matter, which should be chosen to provide the „decomposition“, i.e. the unfolding of thought processes in the solution of educational cognitive tasks and problems. The cognitive tasks are central to the development of the skills underlying transversal competences. That is why the learning process itself is interpreted as a process of solving cognitive tasks. This layout is also the basis of the model of constructivist situational training, as a sequence of learning situations, based on the solution of educational cognitive tasks, followed by tasks of higher difficulty. This requires the development of a system of cognitive educational tasks for the formation and development of relevant transversal competences. Thus, the following groups of tasks have been designed for the development of the competence for cognitive modeling in education: 1) modeling tasks; 2) tasks for recoding information from one type of model to another; 3 ) classification tasks for modeling defining relations; 4) tasks for comparison and modeling of abstractions; 5) generalization tasks for modeling gunusspecies relations; 6) evaluation tasks and tasks for modeling causal relations (Tsankov, 2012: 331-332).

On this basis, the next condition, related to the need to create cognitive situations, enabling the development of transversal com- petences, can be derived. This poses a new requirement related to the structuring of the cognitive information in such a way as to contribute to the establishment of meaning in the acquisition of the educational content.

When analyzing the conditions for the development of transversal competences, account should be taken of the peculiarities of the constructivist concept of the role of the environment. Learning tasks have contextual meaning, i.e, they relate to real problems. The learning environment should present the natural complexity of reality so as to create a condition for assessing the effectiveness and necessity of cognitive activities. All this requires the observance of conditions typical for constructivism and summarized by I. Ivanov (Ivanov, 2004: 155) as follows:

- students should be encouraged to ask questions, make hypotheses and check their correctness;

- students' ideas and experience should be challenged to induce an inner cognitive conflict or hesitation;

- students ${ }^{6}$ mistakes should be seen as positive opportunities for provoking thinking and understanding;

- the environment should provide sufficient opportunities for dialogue, activity and reflection.

This means that the teacher has to:

- engage the students in acquiring experience which contradicts their prior concepts and knowledge;

- allow for students' answers, initiatives and interests to determine the course of the class;

- encourage questions, reasoning and discussion;

- use cognitive terminology of the type "classify", "analyze", "design" when setting tasks;

- stimulate and accept students' autonomy and initiative without losing control of the situation;

- use raw data and primary sources, along with the didactic (interactive, adapted) materials;

- stimulate the use of alternative sources of information;

- encourage students to look for a cause-and-effect explanation of situations and to predict their outcome;

- stimulate self-analysis, argumentation and development (change) of opinions and ideas;

- stimulate learning outside the classroom and the school and help stu- 
dents identify with the problems they solve (Ivanov, 2004: 156).

The above analysis gives grounds for the conditions for the development of transversal competences and the requirements for the relevant environment to be considered synergistically as an integration between the material (means of learning), the socio-psychological (socio-psychological climate, comfort, creativity and teamwork), the psychological (interests, Incentives, readiness for action and preparedness) and the pedagogical (effectiveness, adaptability and performance) conditions in the context of the activity.

Learning, like any human activity, is a complex system whose structure includes interconnected elements that reflect its genesis and development potential. The structure of the cognitive activity includes as its elements needs, motives, goals, tasks, actions, operations, situations and conditions. This approach to the problem of developing transversal competences is inseparably connected to the realization of the main stages of the overall process.

\section{A PROJECT FOR THE DEVELOPMENT OF TRANSVERSAL COMPETENCES (ON THE EXAMPLE OF THE COMPETENCE FOR COGNITIVE MODELING IN EDUCATION)}

Building on the conclusion made for competence as a construct and modeling as a cognitive activity, the competence for cognitive modeling in education should be seen as an integral personality quality, including a system of knowledge, skills (integrated in specific contexts - competencies), and relationships.

Its formation as a predominantly motivated, transversal (portable), strategic rather than functional quality of the personality, the competence for cognitive modeling in education should include: about:

in a meaningful aspect - knowledge

- models and modeling;

- modeling of genus-species relations;

- modeling of causal relations;

- modeling of dependencies and abstractions;

- modeling in experiments;
- modeling processes and phenomena from objective reality in order to explain them;

in an active aspect - skills for:

- investigating objects and revealing their essential features;

- systematizing and summarizing essential information for the object under investigation in a mental, verbal, visual or other form;

- design of models;

- selection of models (selection of the most appropriate model for the situation);

- practical and/or theoretical verification of models;

- coding, decoding and recoding information in and through models;

- transfer of knowledge obtained for the model to knowledge of the subject being studied.

in a personal aspect - the attitude of pupils to cognitive modeling in education:

- as an activity;

- in terms of the results of that activity;

- as a strategy for effective learning (Tsankov, 2013: 33).

In this case knowledge is a ,collection of information" on models and modeling, as well as the possibilities for their application in education; skills are, ,integrative qualities of the personality, acting as a coordinated and integrated series of actions, operations and procedures for achieving certain goals, solving problems and problems" (Radev, 2005: 160), directly related to the realization of the modeling and the utilization of different types of models; the attitude is the students' opinions on the activity and its results, based on the motivation for achievement and interest as the main components of the proclivity for a certain behavior.

Hence, we should consider the competence for cognitive modeling in education as a system of knowledge, skills (competencies or knowledge and skills integrated in a specific context) and relations. When we talk about knowledge, we need to keep in mind not only factual knowledge - the main thing students need to know about modeling and modeling, but also conceptual knowledge (the relationship between knowledge, systematized as elements of larger structures allowing them to function together), as well as procedural and metacognitive knowledge. What procedural knowledge includes is the ways to use 
cognitive modeling, as well as the criteria for using skills, algorithms, methods, techniques and procedures. Metacognitive knowledge is related to knowledge in general, as well as to the actual knowledge of the particular student. It is knowledge of the cognitive tasks, including contextual and conditional knowledge, used in various cognitive situations for modeling which facilitate the reflection of one's own cognitive abilities for modeling. Importantly, what students can master is knowledge related to the modeling patterns that are used in the planning and realization of the cognitive task. And when this knowledge becomes an up-todate modeling process whose subjects are the students themselves, then we can speak about skills. Both knowledge of modeling and models, as well as the skills underlying the competence for cognitive modeling and its practical expression, require systematic and purposeful learning and action, because without knowledge skills cannot be developed.

This requires that, within the framework of the technology for the development of competence forcognitive modeling, knowledge should not be mastered by pupils as an end in itself but as a component of a unified process which realizes the link between knowledge of models and modeling, the development of modeling skills, and the formation of student attitudes towards the activity and its outcomes. On the example of the project for the development of the competence for cognitive modeling as a transversal one (Tsankov, 2010: 34), it is appropriate to seek opportunities to justify basic methodological approaches (Merdzhanova, 2014: 12) as portable and relevant for all educational methods, because the results of their application in education, namely transversal competences, are crucial for personality development.

The above analysis of the essence of students' transversal competences takes into account complex integral personality qualities structured through and interrelated with the goal and result orientation of teaching (and, in a wider context, of education), which establishes conditions for their development as a prerequisite for the improvement of students' cognitive activity and autonomy and for the enhancement of other key competences.

Since competence, as a complex and significant personal construct, influences the overall development and manifestation of the personality, a systemic and holistic approach is needed to develop it. This requires that the transversal competences should be structured and operationalized as a system of competencies that integrate knowledge and skills applicable to a context that overrides separate school subjects and emphasizes students'attitude to the activity and its results. In this sense, the integrity of the learning process, with its suitable and relevant content, procedural aspect (forms, methods, approaches and means) and motivational side (opportunities for motivation and stimulation of interest), allows for the development of transversal competences to their full degree.

This can serve as a foundation for a search for basic methodological approaches to the formation and development of transversal competences on the example of the proposed logical matrix by Y. Merdzhenova - Table 2 (Merdzhanova, 2014: 14).

Table 2. Logical matrix of basic methodological approaches for transversal competences

\begin{tabular}{|c|c|c|}
\hline $\begin{array}{c}\text { Global cultural } \\
\text { idea }\end{array}$ & $\begin{array}{c}\text { Pedagogical } \\
\text { concept }\end{array}$ & $\begin{array}{l}\text { Personality } \\
\text { competence }\end{array}$ \\
\hline $\begin{array}{l}\text { Belonging to the } \\
\text { genus }\end{array}$ & $\begin{array}{l}\text { Genealogical } \\
\text { approach to } \\
\text { man }\end{array}$ & $\begin{array}{l}\text { Genealogical } \\
\text { competence }\end{array}$ \\
\hline Human values & $\begin{array}{l}\text { Axiological } \\
\text { approach to } \\
\text { man }\end{array}$ & $\begin{array}{l}\text { Axiological } \\
\text { competence }\end{array}$ \\
\hline Synergism & $\begin{array}{l}\text { Multi-sensory } \\
\text { approach to } \\
\text { man }\end{array}$ & $\begin{array}{l}\text { Multi-sensory } \\
\text { competence }\end{array}$ \\
\hline Interculturalism & $\begin{array}{l}\text { Interdisciplinary } \\
\text { approach to } \\
\text { human } \\
\text { knowledge }\end{array}$ & $\begin{array}{l}\text { Interdisciplinary } \\
\text { competence }\end{array}$ \\
\hline $\begin{array}{l}\text { Hologramic/Three- } \\
\text { dimensional } \\
\text { existence }\end{array}$ & $\begin{array}{l}\text { Approach of the } \\
\text { dynamic } \\
\text { modeling }\end{array}$ & $\begin{array}{l}\text { Prognostic } \\
\text { competence }\end{array}$ \\
\hline $\begin{array}{l}\text { Differentiation and } \\
\text { specialization }\end{array}$ & Expert approach & $\begin{array}{l}\text { Expert } \\
\text { competence }\end{array}$ \\
\hline Globalization & $\begin{array}{l}\text { Regional and } \\
\text { historical } \\
\text { approach to } \\
\text { man }\end{array}$ & $\begin{array}{l}\text { Integrating } \\
\text { competence }\end{array}$ \\
\hline
\end{tabular}

This requires that modern research in the field of education seek opportunities to: 1) develop a conceptualized and operationalized transversal model that allows to distinguish and identify the core competencies (knowledge and skills integrated into specific contexts) whose systematic and purposeful development should be subject to approbation and verification; 2) design a project and didactic invariant technology for the formation of transversal competence in the education of students at all degrees and stages that will be approbated and applied extensively in the training on different subjects in order to prove its applicability and portability through different activities and ages. 
It is expedient to systematise and specify the opportunities for the formation and development of transversal competences within the curriculum of all subjects as well as the expected results at the level of the educational documentation. The systematic and goal-oriented implementation of basic methodological approaches and technologies for the development of transversal competences is also related to the observance of specific didactic principles and conditions in order to ensure the necessary efficiency. This necessitates the special training and qualification of teachers.

All of this is a basis for expanding the research curriculum with regard to: 1) the relation curriculum - transversal competences because it is interesting how they integrate into curricula due to their interdisciplinary status; 2 ) the design of the educational environment in modern schools; 3) the expectations from students and teachers; 4) the transformation of the professional training of modern teachers; 5 ) the ways to form the professional profile of the teacher as an expert, consultant, mediator and moderator in the course of the formation and development of students' transversal competences.

\section{Conflict of interests}

The author declare no conflict of interest.

\section{REFERENCES}

Burke, J. (1989). Competency Based Training and Education. Lewis: Palmer Press.

Delibaltova, V. (2003). Towards competence as an object of didactic interest. Pedagogy, 2, 10-16, (In Bulgarian)

Desev, D. (1999). Dictionary of psychology. Sofia: Bulgarika (In Bulgarian).

Dimova, D.(2013). Contemporary models in the constructivist design of education. Vocational Education, 5(1), 24-37, (In Bulgarian).

Genkova, L. (2007). On a competence approach to the quality of chemistry teaching and education. Chemistry, 16 (6), 438-446, (In Bulgarian).

Gyurova, V., V. Bozhilova, V. Valkanova, G. Dermendzhieva (2006). Interactivity in the educational process. Sofia: EVROPRESS, (In Bulgarian).

Gyuviiska, V. (2012). The return to studying as coexistence. Philosophy, 21(3), 270-282, (In Bulgarian). http://www.azbuki.bg/editions/journals/ philosophy/contents/pkilcont032012\#art07

Hutorskoy, A. (2001). Contemporary didactics. University course book. Saint Petersburg, (In Russian).

Hutorskoy, A. V. (2003). Key competences as a component of personality-oriented education. National education, 2, 58-64, (In Russian).

Ivanov, I. (2004) Theories of education. Shumen, (In Bulgarian).

Kolb, D. A. (1984). Experiential learning: Experience as the source of learning and development, Vol.
1. Englewood Cliffs, NJ: Prentice-Hall.

Langacker, R. (1987). Foundations of Cognitive Grammar. Vol. 1. Stanford: Stanford University Press.

Levunlieva, M. (2012). The process aspects of communication as a phenomenon and as a concept. Foreign Language Teaching, 39 (2), 173-183.

Lyons, J. (1977). Semantics. Vol. 1 \& 2. Cambridge: Cambridge University Press.

Merdzhanova, Y. (2002). Transversal competences of the student - e case study. Annual journal of $S U$ "St. Kliment Ohridski", (97-141), (In Bulgarian).

Merdzhanova, Y. (2005). The multisensory principle in education and in life. Sofia: University Publishing House "St. Kliment Ohridski", (In Bulgarian).

Merdzhanova, Y. (2014). Basic methodological approaches to transversal competences. Sofia: University Publishing House "St. KlimentOhridski”, (In Bulgarian).

Naydenova, V. (2004). The professional image of the modern techer (on the example of the Chemistry specialist), Sofia, (In Bulgarian).

Petrov, P., M. Atanasova (2001). Educational technologies and learning strategies. Sofia, (In Bulgarian).

Prange, K. (1995). Über das Zeigen als operative Basis der pädagogischen Kompetenz. In: Bildung und Erziehung 48, Heft 2, (145-158)

Radev, Pl. (2005). General school didactics. Plovdiv: University Pubkishing House "Paisii Hilendarski", (In Bulgarian).

Radev, Pl. (2013). Encyclopaedia of education sciences. Plovdiv: University Pubkishing House "Paisii Hilendarski”, (In Bulgarian).

Raven, J. (1999). Testing in education: problems, misconceptions, perspectives. Moscow: Kogito tsentr, (In Russian).

Ray, B. (1996). Les competences transversales en question Collection Pedagogies. Paris: ESF.

Selevko, G. (2004). Competences and their classification. National education. 4, 138-143, (In Russian).

Tafrova-Grigorova, A. (2016). Historical roots and development of constructivism. Chemistry: Bulgarian Journal of Science Education. 25 (1), 75-106, (In Bulgarian). http://khimiya.org/pdfs/ CHEMISTRY_25_1_TAFROVA.pdf

Talmy, L. (2000). Tow $\bar{w}$ ard $\bar{a}$ Cognitive Semantics. Vol. 1. Concept Structuring Systems. Cambridge \& Mass \& London: MIT Press.

Temyatkina, O. V. (2006). Forming key competences in students during the educational process. Dissertation abstract, Yekaterinburg, (In Russian).

Tsankov, N. (2010). A project for the development of competence for cognitve modelling in education. Pedagogy, 2, 34-54, (In Bulgarian).

Tsankov, N. (2010). Invariant technology for the development of a competence for cognitive modelling in education. Pedagogy, 6, 45-59, (In Bulgarian).

Tsankov, N. (2012). Educational and cognitive tasks for the formation and development of competence for modelling in Chemistry and Environmental Sciences. Chemistry: Bulgarian Journal of Science Education, 21 (3), 327-340, (In Bulgarian). http://khimiya.org/show_issue. php? $y=2012$ \&vol $=21$ \&issue $=3 \& i$ id $=36 \overline{\# 327}$

Tsankov, N. (2012). The concept-event pair competence - competency in education sciences. Romanian 
(IJCRSEE) International Journal of Cognitive Research in Science, Engineering and Education Vol. 5, No. 2, 2017.

Journal of School Psychology, Vol. 5, No. 9, 4352. http://www.anps.ro/documente/Revista $\% 20$ nr\%209/abstract\%20Tsankov.pdf

Tsankov, N. (2013). Competence for cognitive modelling (didactic concretization and development). Sofia: Avangard Prima, (In Bulgarian).

Tsvetkova, Y. (2001). Motivational and cognitive regulation in learning. Sofia: LiK, (In Bulgarian).

Vasilev, V., Y. Dimova, T. Kolarova - Kancheva (2005). Reflection and education. Plovdiv: Makros, (In Bulgarian).

Velikova, V. (2003). Educational competence as an outcome of the educational activity. Pedagogy, 6 3-19, (In Bulgarian).

Zeer, E. F. (1999). Personality-oriented professional education. Ekaterinburg, Ural (In Russian).

Zimnaya, I. A. (2006). Kompetentnostnyy podkhod. Kakovo ego mesto v sisteme sovremennykh podkhodov k probleme obrazovaniya? [Competence approach. What is its place in the system of modern approaches to the problem of education?]. Vysshee obrazovanie segodnya, 8, 20-26. 